\title{
Disordered hepcidin-ferroportin signaling promotes breast cancer growth
}

\author{
Shuping Zhang a,b ${ }^{\text {, Yue Chen }}{ }^{\mathrm{a}, \mathrm{c}}$, Wenli Guo ${ }^{\mathrm{a}}$, Lin Yuan ${ }^{\mathrm{d}}$, Daoqiang Zhang ${ }^{\mathrm{d}}$, Yong Xu ${ }^{\mathrm{c}}$, Elizabeta Nemeth ${ }^{\mathrm{e}}$, \\ Tomas Ganz ${ }^{\mathrm{e}}$, Sijin Liu ${ }^{\text {a,* }}$ \\ a State Key Laboratory of Environmental Chemistry and Ecotoxicology, Research Center for Eco-Environmental Sciences, Chinese Academy of Sciences, Beijing 100085, China \\ ${ }^{\mathrm{b}}$ Institute for Medical Engineering and Science, Massachusetts Institute of Technology, Cambridge, MA 02139, USA \\ c Department of Urology, The Second Hospital of Tianjin Medical University, Tianjin Institute of Urology, Tianjin 300211, China \\ d Weifang Medical College, Wendeng Central Hospital, Weihai 264400, China \\ e Department of Medicine, David Geffen School of Medicine, University of California - Los Angeles, Los Angeles, CA 90095, USA
}

\section{A R T I C L E I N F O}

\section{Article history:}

Received 24 May 2014

Received in revised form 26 June 2014

Accepted 28 July 2014

Available online 3 August 2014

\section{Keywords:}

Iron

Hepcidin

Ferroportin

Breast cancer

\begin{abstract}
A B S T R A C T
Iron homeostasis is strictly governed in mammals; however, disordered iron metabolism (such as excess iron burden) is recognized as a risk factor for various types of diseases including cancers. Burgeoning evidence indicates that the central signaling of iron homeostasis, the hepcidin-ferroportin axis, is misregulated in cancers. Nonetheless, the mechanisms of misregulated expression of iron-related genes along this signaling in cancers remain largely unknown. In the current study, we found increased levels of serum hepcidin in breast cancer patients. Reduction of hepatic hepcidin through administration of heparin restrained tumorigenic properties of breast tumor cells. Mechanistic investigation revealed that increased iron, bone morphogenetic protein- 6 (BMP6) and interleukin-6 (IL-6) jointly promoted the synthesis of hepatic hepcidin. Tumor hepcidin expression was marginally increased in breast tumors relative to adjacent tissues. In contrast, tumor ferroportin concentration was greatly reduced in breast tumors, especially in malignant tumors, compared to adjacent tissues. Elevation of ferroportin concentration inhibited cell proliferation in vitro and in vivo by knocking down tumor hepcidin expression. Additionally, increased IL- 6 was demonstrated to jointly enhance the tumorigenic effects of iron through enforcing cell growth. Our combined data overall deciphered the machinery that altered the hepcidin-ferroportin signaling in breast cancers. Thus, targeting the hepcidin-ferroportin signaling would represent a promising therapeutics to restrain breast cancer growth.
\end{abstract}

(c) 2014 Elsevier Inc. All rights reserved.

\section{Introduction}

Mammalian cells have a fine-tuned regulatory system to maintain iron balance. However, misregulation of this system would elicit detrimental effects on cells, such as the oncogenic effect of intracellularly retained free iron [1,2]. Deregulated systemic iron homeostasis contributes to cancer risk and progression $[2,3]$. The contributory role of iron in cancers could be mediated by: a) overproduction of ROS and free radicals through iron-dependent Fenton reaction; b) induction of oxidative stress-responsive transcriptional factors and pro-inflammatory cytokines; c) iron-mediated hypoxia signaling; and

Abbreviations: LIP, labile iron pool; FAC, Ferric Ammonium Citrate; DCF-DA, dichlorofluorescein-diacetate; PI, propidium iodide; IO, iron-overloaded; MFPs, mammary fat pads; IP, intraperitoneal injection; CA-AM, calcein acetoxymethyl ester; FACS, Fluorescence Activated Cell Sorting; H\&E, hematoxylin and eosin; Abs, antibodies; NAC, $\mathrm{N}$-acetyl-cysteine; ROS, reactive oxygen species; ID, iron-deficient; IV, intravenous injection; PBS, phosphate-buffered saline; DFO, Deferoxamine; DAB, diaminobenzidine.

* Corresponding author. Tel./fax: +861062849330

E-mail address: sjliu@rcees.ac.cn (S. Liu). d) promotion of DNA synthesis driven by iron-containing ribonucleotide reductase [4].

Although studies of iron have been ongoing for a long time, the molecular bases of systemic iron homeostasis were only recently identified with the characterization of the hepcidin-ferroportin axis $[5,6]$. Hepcidin, a peptide hormone, is prominently synthesized by the liver, and secreted into serum followed by tissue localization through circulation [7]. Hepcidin inhibits iron absorption from the duodenum and iron egress from macrophages and hepatocytes through its binding and inducing degradation of iron exporter ferroportin [8]. Deregulated hepcidin-ferroportin signaling is implicated not only in iron diseases, e.g. hereditary hemochromatosis and anemia of inflammation $[5,9,10]$, but also in cancers [11-13]. Previous studies have revealed that increased serum hepcidin accompanies multiple cancers, such as myeloma, renal cell carcinoma and prostate cancer $[11,12,14,15]$; however, the effects of abnormal circulating hepcidin on tumor behaviors remain unexploited. Moreover, recent studies suggest that iron metabolism in cancer cells themselves is also adapted for the enhanced demand of iron necessary for rapid growth of cancer cells [2]. Tumor cells were also noted to express hepcidin and its receptor 
ferroportin $[15,16]$. Moreover, reduced ferroportin expression correlated with poor prognosis, with a better survival rate for patients with high ferroportin levels in cancer patients $[13,17]$. Nonetheless, studies of the adaptive metabolism for tumor iron that facilitates cell growth are still rare, and the molecular mechanisms responsible for abnormal regulation of hepcidin/ferroportin in tumor cells remain elusive. In this study, we aim to elucidate the molecular bases underlying the misregulated hepcidin-ferroportin signaling in breast cancers. Our combined data highlight an important role of the disordered hepcidin-ferroportin signaling in promoting breast cancer growth, and provide a rationale for targeting this signaling for the therapeutics of breast cancers.

\section{Materials and methods}

\subsection{Cell culture}

Human breast cancer cell lines MDA-MB-231, MCF-7, T47D and SKBR-3, mouse breast cancer cell line 4T1, and human hepatic carcinoma cell lines SMMC-7721 and HepG2 and hepatic epithelial cell line L-02 were obtained from the Shanghai Cell Bank of Type Culture Collection of Chinese Academy of Sciences. Cells were cultured in RPMI 1640 medium (Gibco), supplemented with $10 \%$ fetal bovine serum (FBS, Hyclone) and $100 \mathrm{U} / \mathrm{ml}$ penicillin-streptomycin (Hyclone) at $37{ }^{\circ} \mathrm{C}$ under $5 \% \mathrm{CO}_{2}$.

\subsection{Clinical specimens}

All sera and tumor specimens were obtained from Weihai Wendeng Central Hospital, China, with written consent in accordance with the regulations of the Institutional Ethics Committee. Overall, 155 sporadic breast cancer patients were enlisted with an average age of $47.25 \pm$ 0.74 years old, and breast cancers were diagnosed based on surgical and pathological characteristics. Blood samples were collected prior to any therapeutics and surgery. Tumor specimens were obtained from the initial surgery for all patients. Healthy controls were age-matched healthy women ( $48.07 \pm 0.98$ years old) who were selected from the same local district and had no history of tumors, systemic disorders, liver diseases, and inflammatory diseases. Healthy individuals provided informed consent for anonymous use of their blood for scientific research. All fresh specimens were immediately frozen under $-80{ }^{\circ} \mathrm{C}$ for future analyses.

\subsection{Animal experiments}

All animal care and surgical procedures were approved by the Animal Ethics Committee at the Research Center for Eco-Environmental Sciences, Chinese Academy of Sciences. All mice were purchased from the Vital River Laboratories, China and housed under a sterile and pathogen-free environment. Human breast cancer MDA-MB-231 cells and mouse breast cancer 4T1 cells were used to study in vivo tumorigenesis and tumor growth. The experimental setup for cancer cell inoculation and tumor graft implantation was similar to the methods described previously $[18,19]$. Tumor growth was monitored every $2-4$ days measuring the tumor size with a vernier caliper by a blinded observer and calculating according to the formula $\pi / 6 \times \mathrm{L} \times \mathrm{W}^{2}$. Mice were sacrificed when tumors reached a size of $1.0 \mathrm{~cm}^{3}$ or caused significant morbidity to animals. Tumorigenic rate was calculated by dividing the number of tumor-bearing mice by the number of total mice in each group.

\subsection{Mouse models of iron overload and iron deficiency}

Iron overload was induced through intraperitoneal injection (IP) of iron-dextran (Sigma-Aldrich) into Balb/c mice at $250 \mathrm{mg} / \mathrm{kg}$ body weight twice a week for 4 weeks, similar to a previous study [20]. To induce iron deficiency, Balb/c mice were put on an iron-deficient diet for 4 weeks as previously described [21].

\subsection{RNA extraction and $q R T-P C R$ analysis}

Total RNAs were isolated from cells using TRIzol (Invitrogen) according to the manufacturer's instructions. Tissue samples were first pulverized in liquid nitrogen and then total RNAs were extracted with TriPure (Roche) following the instruction provided by the manufacturer. Quantitative measurements of gene expression were carried out with SYBR Green qPCR master mix (Qiagen) on qPCR Systems Mx3005P (Stratagene). GAPDH or HPRT1 was used as an internal control for human or mouse samples, respectively. Primer sequences are shown in Table 1.

\subsection{Western blotting and ELISA assay}

Cultured cells after treatments were harvested and washed twice with phosphate-buffered saline (PBS). Total proteins were extracted with ice-cold RIPA lysis buffer (Solarbio, China) containing protease inhibitor cocktail (Roche). Solid tissues were snap-frozen in liquid nitrogen and homogenized in the abovementioned lysis buffer. Equal amounts of protein lysates (30-50 $\mu \mathrm{g} /$ sample) were subject to $8-12 \%$ SDS-PAGE and Western blot analysis as described previously [22]. Antibodies were anti-GAPDH (1:1000, Santa Cruz Biotechnology), ferritin light chain antibody (1:500, Abcam) and ferroportin antibody (1:500, Sigma-Aldrich).

The concentrations of BMP6, BMP4, IL-6 and hepcidin were measured in sera from breast cancer patients and healthy individuals using ELISA kits according to the manufacturer's instructions (BMP6 and BMP4 kits from RayBiotech, IL-6 kit from R\&D and hepcidin kit from DRG).

\subsection{Determination of iron content, intracellular labile iron pool (LIP)} measurement and iron staining

Serum iron content was determined with a kit following the manufacturer's instructions (Nanjing Jiancheng Bioengineering Institute, China). Tissue non-heme iron was assayed as previously described [23]. The intracellular LIP level was determined according to an established method [24]. Briefly, cells were collected and washed twice with PBS, followed by incubation with $0.5 \mu \mathrm{M}$ CA-AM (calcein acetoxymethyl ester) (Sigma-Aldrich) for $15 \mathrm{~min}$ at $37^{\circ} \mathrm{C}$. Thereafter, cells were washed twice with PBS and were then equally divided into two parts with one treated with $100 \mu \mathrm{M}$ DFO (Sigma-Aldrich) for $1 \mathrm{~h}$ at $37^{\circ} \mathrm{C}$ and the other left untreated. Calcein was excited at $488 \mathrm{~nm}$ and measured at $525 \mathrm{~nm}$ with a flow cytometer (BD, FACSCalibur). The intracellular LIP was calculated after deduction of the cellular fluorescence in DFO-treated cells by that in the untreated cells.

Table 1

Oligonucleotide primers for qRT-PCR.

\begin{tabular}{ll}
\hline Name & Sequence $\left(5^{\prime} \rightarrow 3^{\prime}\right)$ \\
\hline hsa_hepcidin sense & CCTGACCAGTGGCTCTGTTT \\
hsa_hepcidin anti-sense & CACATCCCACACTTTGATCG \\
hsa_ferroportin sense & ACCTCGCTGGTGGTACAGAATGTT \\
hsa_ferroportin anti-sense & AGCAGGAAGTGAGAACCCATCCAT \\
hsa_GAPDH sense & GAAGGTGAAGGTCGGAGT \\
hsa_GAPDH anti-sense & GAAGATGGTGATGGGATTTC \\
mmu_hepcidin sense & CTGAGCAGCACCACCTATCTC \\
mmu_hepcidin anti-sense & TGGCTCTAGGCTATGTTTGC \\
mmu_BMP6 sense & AACGCCCTGTCCAATGACG \\
mmu_BMP6 anti-sense & ACTCTTGCGGTTCAAGGAGTG \\
mmu_IL-6 sense & CTGCAAGAGACTTCCATCCAG \\
mmu_IL-6 anti-sense & AGTGGTATAGACAGGTCTGTTGG \\
mmu_HPRT1 sense & GCTTGCTGGTGAAAAGGACCTCTCGAAG \\
mmu_HPRT1 anti-sense & CCCTGAAGTACTCATTATAGTCAAGGGCAT \\
\hline
\end{tabular}


Tumor tissues were fixed in $10 \%$ buffered formaldehyde and embedded in paraffin. Deparaffinized sections were treated with $1 \%$ hydrogen peroxide $\left(\mathrm{H}_{2} \mathrm{O}_{2}\right)$ for $10 \mathrm{~min}$ to eliminate the activity of endogenous peroxidase. Thereafter, tumor iron staining was determined following the method of Perl's iron staining with the enhancement of diaminobenzidine (DAB, Sigma-Aldrich), as previously described [25]. Slides were counter-stained with Alcian Blue (Sigma-Aldrich). Hematoxylin and eosin (H\&E) staining was performed on the slides from the same blocks.

\subsection{BMP6/IL-6 neutralization and iron chelation assays}

Sera from 10 patients with similar concentrations of iron, BMP6 and IL- 6 to the averages of the whole patients were pooled together for the following cell treatments and blockade experiments. Hepatic SMMC7721 cells were first cultured with $10 \%$ human sera. The neutralization treatment was then conducted with administration of an IL-6 neutralizing $\mathrm{Ab}$ (Biosynthesis Biotechnology, China) or a BMP6 neutralizing $\mathrm{Ab}(\mathrm{R} \& \mathrm{D})$ at $6 \mu \mathrm{g} / \mathrm{ml}$. An equal amount of normal IgG (Santa Cruz Biotechnology) was used as a control. Iron chelation was performed with $100 \mu \mathrm{M}$ DFO (Sigma-Aldrich). After treatment for $24 \mathrm{~h}$, total RNAs were extracted for hepcidin expression analysis by qRT-PCR, or $48 \mathrm{~h}$ later, cell morphology and proliferation were assessed.

\subsection{Cell proliferation assay and colony formation assay}

Cell growth was determined by MTT assay (Roche) and BrdU incorporation assay (Roche). Briefly, cells were starved in serum-free medium overnight and then seeded at a concentration of $5.0 \times 10^{3}$ cells/ well in 96-well plates with different treatments. Cell culture continued for $48 \mathrm{~h}$, and then cell growth was assessed following the instructions provided by the manufacturer. Regarding colony formation assay, single cell suspension at a density of 5 cells/ml was prepared and then was inoculated into 96-well plates with $100 \mu \mathrm{l}$ per well. At $4 \mathrm{~h}$ post-cell inoculation, all 96 wells were checked under a microscope and the wells with only one cell were selected for the follow-up observation. Cells were cultured with $10 \%$ FBS and observed for up to 12 days. Numbers of wells containing colonies were recorded on day 12, and the percentage of colony formation was calculated.

\subsection{Intracellular ROS determination}

Intracellular ROS (reactive oxygen species) was spectrophotometrically examined with dichlorofluorescein-diacetate (DCF-DA, Sigma) as described previously [19]. Briefly, after starvation in serum-free medium overnight, MDA-MB-231 cells were seeded in 96-well plates with $1.5 \times 10^{4}$ cells/well. Cells were pre-incubated with DCF-DA at $5 \mu \mathrm{M}$ for $30 \mathrm{~min}$ and then treated with $32 \mu \mathrm{M}$ FAC (Ferric Ammonium Citrate) with or without NAC (N-acetyl-cysteine, $10 \mathrm{mM}$, SigmaAldrich) or $100 \mu \mathrm{M}$ DFO for $2 \mathrm{~h}(\mathrm{n}=6)$. After washing 3 times with PBS, DCF fluorescence was determined at an excitation wavelength of $485 \mathrm{~nm}$ and an emission wavelength of $530 \mathrm{~nm}$ on a fluorescent plate reader (Thermo).

\subsection{Cell death assessment}

Cell death was assessed by FACS analysis with Annexin V and propidium iodide (PI) staining (BD Biosciences) as described [19]. Briefly, cells were starved overnight and then seeded in 6-well plates with $1.0 \times 10^{5}$ cells/well. After different treatments for $24 \mathrm{~h}$, cells were collected and washed with PBS, followed by FACS analysis of apoptosis and necrosis.

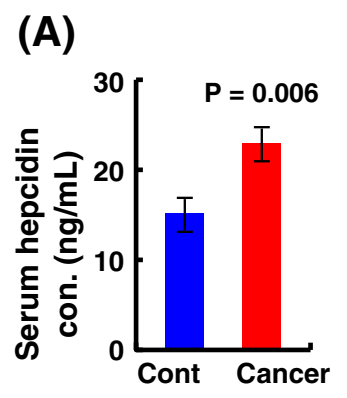

(B)

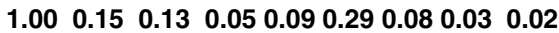

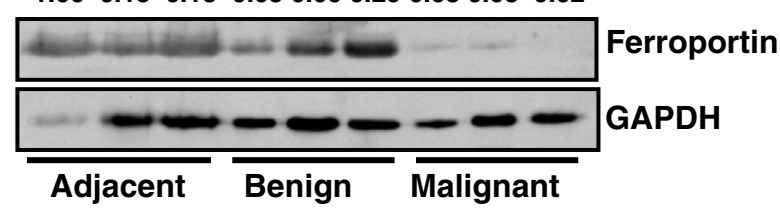

Fig. 1. Abnormal hepcidin-ferroportin signaling in breast cancer patients. (A) Hepcidin concentration in sera from breast cancer patients $(n=91)$ and healthy women $(n=$ 51) assessed by ELISA. (B) A representative image of Western blot showing ferroportin protein concentration in adjacent tissues, benign tumors and malignant tumors.

\subsection{Viral construct infection and plasmid transfection}

MDA-MB-231 cells were infected with lentiviral-based transduction particles (Sigma-Aldrich) of hepcidin and non-target shRNAs (scrambled control). Hepcidin shRNA transduction particles were composed of 3 constructs, targeting different regions of the corresponding mRNAs. Stable transfectants were obtained 15 days after selection with puromycin (10 $\mu \mathrm{g} / \mathrm{ml}$, Sigma-Aldrich).

\subsection{Inhibition of hepatic hepcidin}

The efficacy of heparin (heparin sodium salt, Sigma-Aldrich) was assessed in hepatic cells. Cells were starved for $12 \mathrm{~h}$ in medium with

\section{(A)}

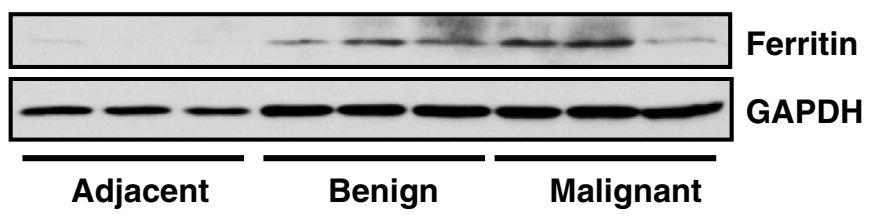

(B)

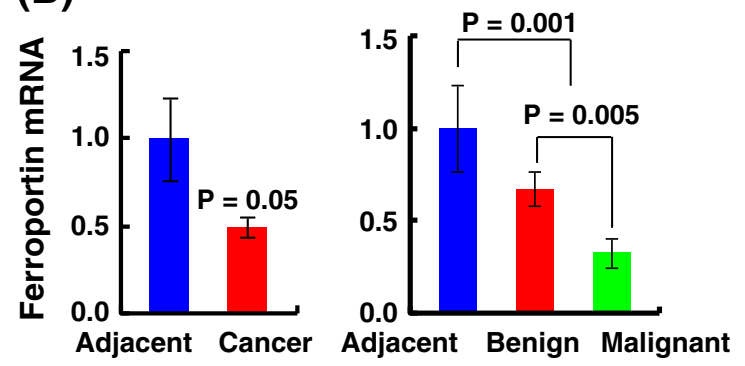

Fig. 2. Ferritin and ferroportin concentrations in breast tumors. (A) A representative image of ferritin protein concentration in adjacent tissues, benign tumors and malignant tumors determined by Western blot. (B) Ferroportin mRNA level in adjacent tissues $(n=21)$, benign tumors $(n=47)$ and malignant tumors $(n=49)$. 

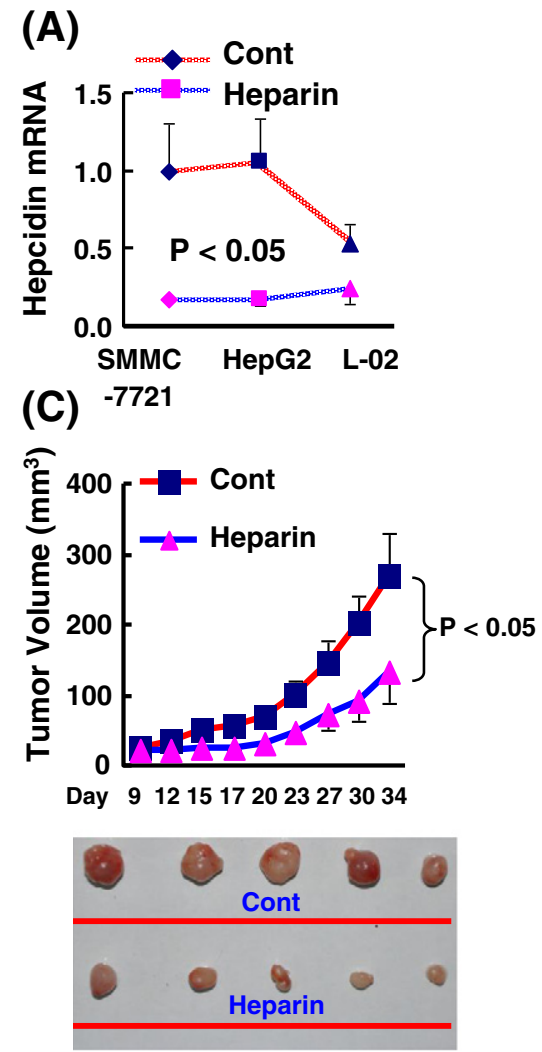

(D)

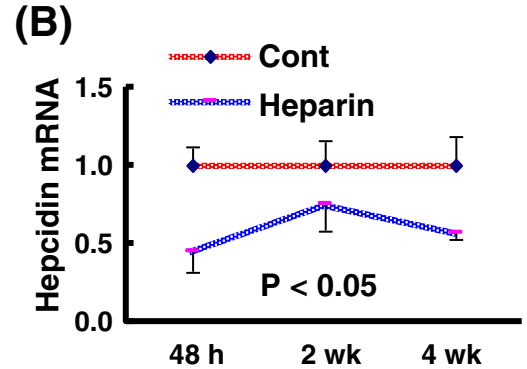

(E)
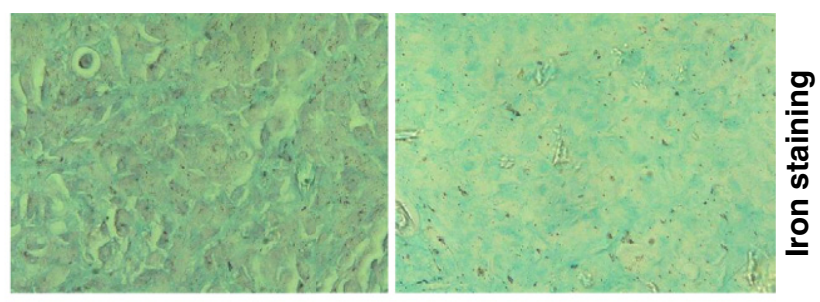

Heparin

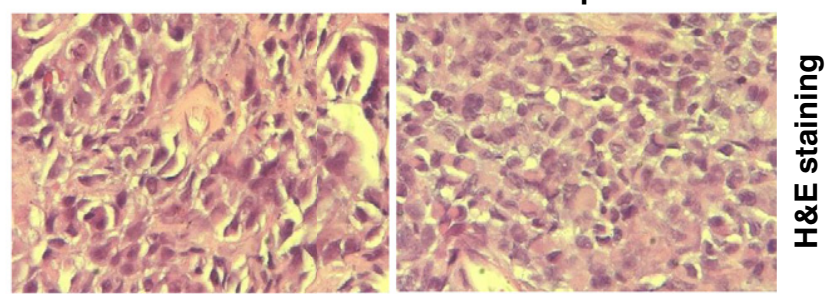

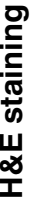

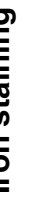

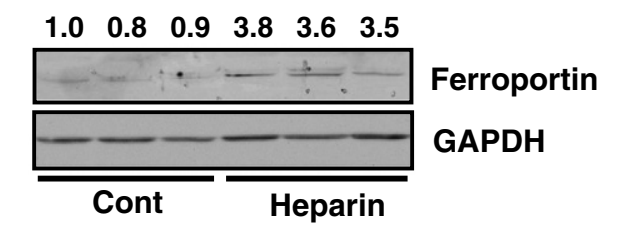

(F)
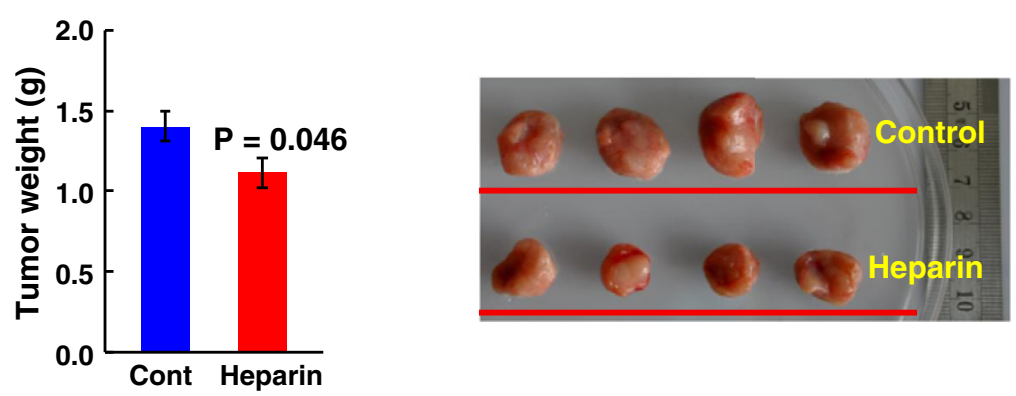

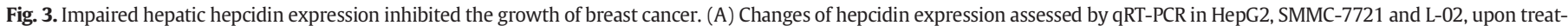

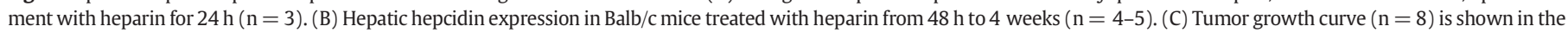

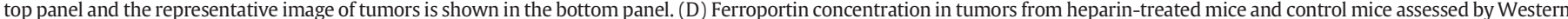

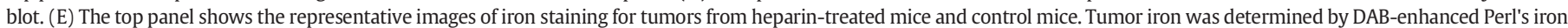

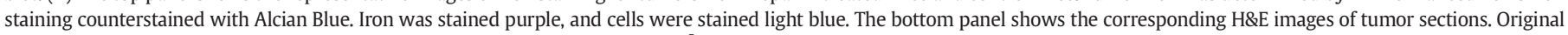

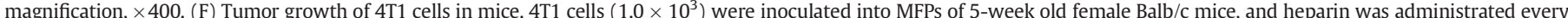

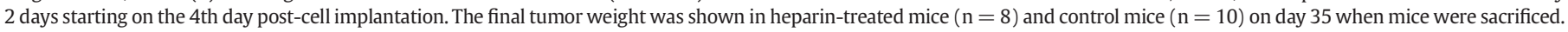

$1 \%$ FBS, and cultured with $4 \mu \mathrm{g} / \mathrm{ml}$ heparin for another $24 \mathrm{~h}$. The hepcidin mRNA level was then determined by qRT-PCR. For the inhibition of hepatic hepcidin expression in animals, Balb/c mice received intravenous injection (IV) of heparin resolved in PBS at a concentration of
$8 \mathrm{mg} / \mathrm{kg}$ body weight every 2 days up to 4 weeks. For tumor growth assay, nude (nu/nu), Balb/c or SCID/beige mice received IV injection of heparin at $8 \mathrm{mg} / \mathrm{kg}$ body weight beginning on the 4 th day after tumor implantation. Control mice received PBS. 
(A)

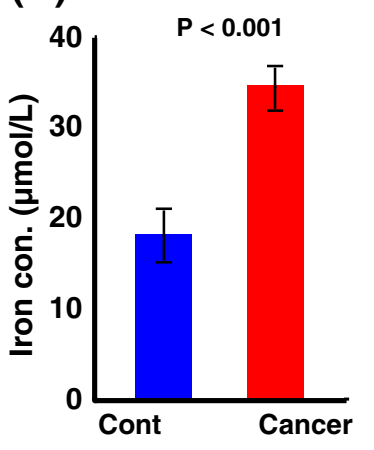

(D)

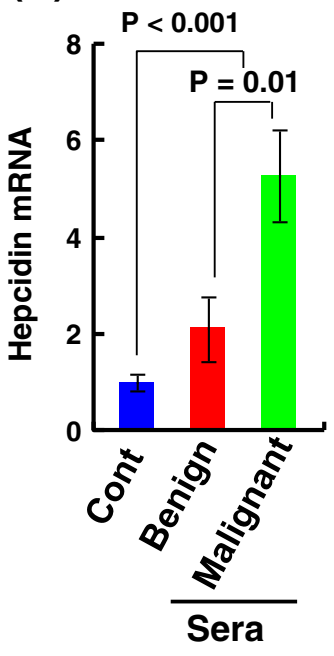

(B)

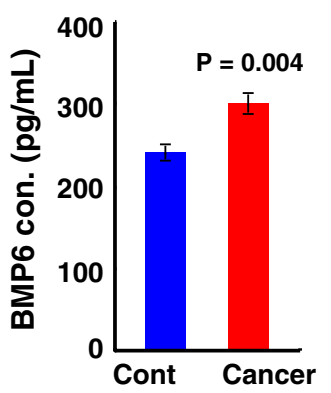

(C)

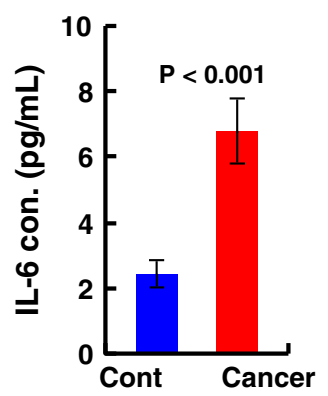

(E)

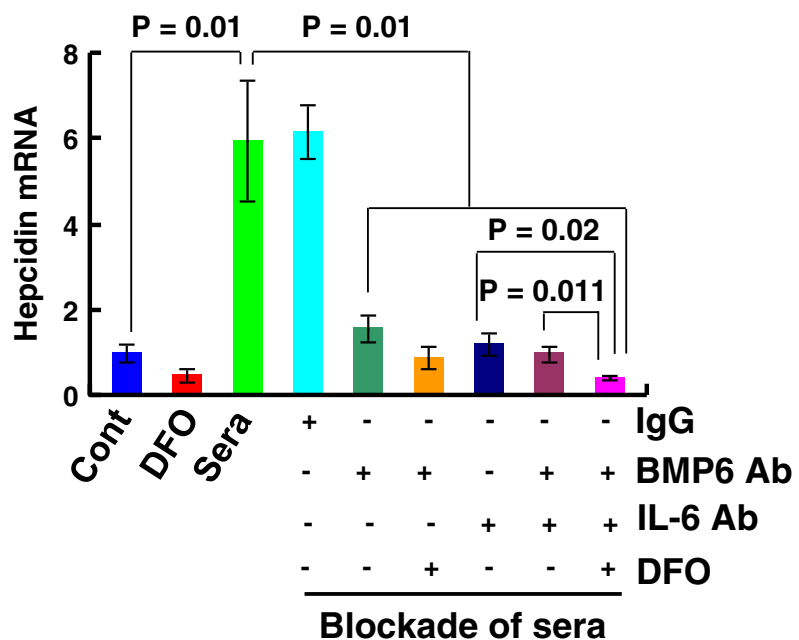

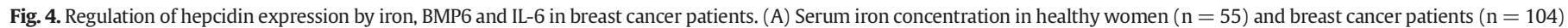

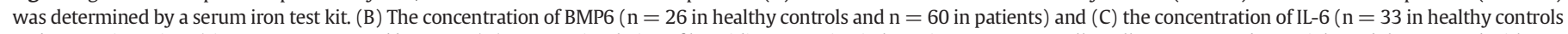

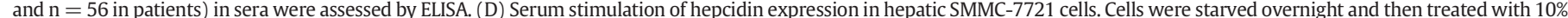

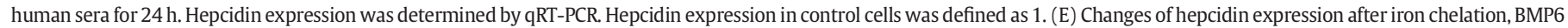

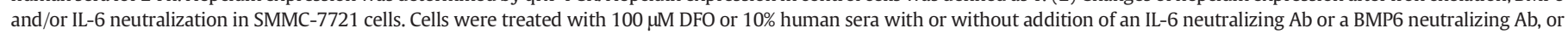
normal IgG $(\mathrm{n}=4-6)$. After $24 \mathrm{~h}$, qRT-PCR was conducted to assess hepcidin level. Hepcidin expression in control cells was defined as 1.

\subsection{Quantification of images and statistical analysis}

The intensities of autoradiogram in Western blots and PCR bands in agarose gels were quantified with the software Image $(\mathrm{NIH})$, and quantified data of each protein/gene were normalized with those of the loading control. Independent $t$ test or one-way ANOVA test was used to analyze the experimental data. Data were shown in mean \pm SE. P $<0.05$ was considered statistically significant.

\section{Results}

\subsection{Increased hepcidin in sera from breast cancer patients}

Hepcidin is prominently expressed by hepatocytes, secreted into plasma and distributed into tissues through blood circulation $[7,26]$. Although previous studies have documented elevated serum hepcidin in patients with myeloma, renal cell carcinoma and prostate cancer $[11,12,14,15]$, serum hepcidin concentrations in breast cancers have not been reported yet. To this end, we measured serum hepcidin from breast cancer patients and healthy women at a similar average age. As shown in Fig. 1A, serum hepcidin concentration was increased by more than $50 \%$ in breast cancer patients compared to that in the healthy controls $(\mathrm{P}<0.05)$. This observation is similar to those in other cancers $[11,12,14,15]$. This finding also implied a positive association between increased circulating hepcidin and breast cancer development.

Subject to enforced serum hepcidin level, the ferroportin protein level was reduced in tumors, especially in malignant tumors (approximately 11 fold), compared to adjacent tissues (Figs. 1B and S1). As a result, increased intracellular iron concentration was observed in tumors, as reflected by the elevated level of ferritin light chain, compared to adjacent tissues (approximately 23 fold for benign tumors and 29 fold for malignant tumors) (Figs. 2A and S2). Similar alterations were seen at the mRNA level for ferroportin, as reduced by $67 \%$ compared to adjacent tissues $(\mathrm{P}<0.05)$; in malignant tumors, its level was further reduced compared to benign tumors and adjacent tissues (Fig. 2B, $\mathrm{P}<0.05$ ). The finding of diminished ferroportin in breast tumor specimens is in accordance with the previous statement that low ferroportin expression predicts much worse metastasis-free survival than high ferroportin expression [13]. The molecular mechanisms responsible for diminished ferroportin expression in breast tumors warrant further close investigation. Nonetheless, these data thus 
(A)

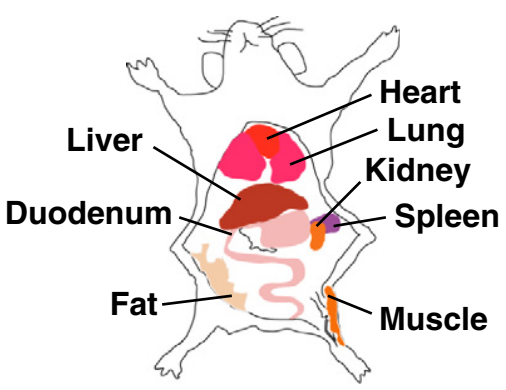

(B)

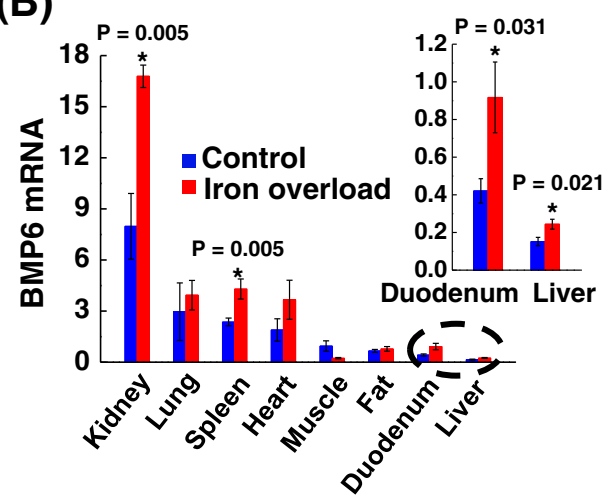

(C)

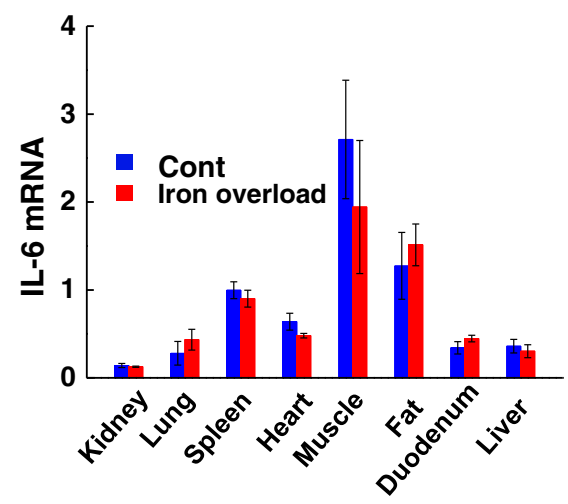

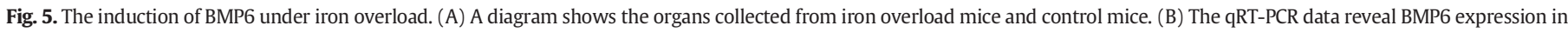

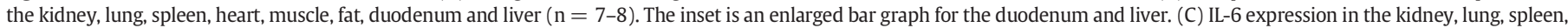
heart, muscle, fat, duodenum and liver $(\mathrm{n}=7-8)$ from iron-overloaded mice and control mice analyzed by qRT-PCR.

revealed a great contribution of enforced serum hepcidin and reduced tumor ferroportin to cancer progression.

\subsection{Reduction of hepatic hepcidin suppressed tumor growth}

To look into the role of serum hepcidin (derived from the liver) in affecting tumor growth, we inhibited liver-derived hepcidin in mice. Heparin was recently reported to be a potent inhibitor of liver-derived hepcidin production [27]. In pilot experiments, the qRT-PCR results indicated that hepcidin expression was suppressed in all 3 human hepatic cell lines, HepG2, SMMC-7721 and L-02 (by $>50 \%$, Fig. 3A, P $<0.05$ ). Similar to the in vitro results, hepatic hepcidin was suppressed in mice intravenous injection IV treated with heparin from 48 h to 4 weeks (Fig. 3B, $\mathrm{P}<0.05$ ). It should be noted that heparin had little effect on cell survival of breast cancer MDA-MB-231 and MCF-7 cells (data not shown). We then studied the effect of hepatic hepcidin reduction on tumor growth by orthotopically implanting tumor grafts derived from MDA-MB-231 cells into mammary fat pads (MFPs) of 5-week old female nu/nu mice. Heparin was given every 2 days starting on the 4th day post-tumor implantation. Tumor growth was remarkably inhibited, and the final tumor weight was reduced by $48 \%$ in mice with heparin administration in comparison to those in the control mice (Figs. 3C and S3A, P $<0.05$ ). We also observed an expected consequence of hepcidin suppression: a large increase of ferroportin concentration as evidenced by Western blot in tumors from mice administrated with heparin (Figs. 3D and S3B, P < 0.05). As a result, the intracellular iron content in tumor cells was greatly reduced, as determined by tumor iron staining (Fig. 3E). We next evaluated the influence of hepatic hepcidin reduction on tumor growth of mouse breast cancer 4T1 cells in mice. The tumor growth of 4T1 cells was slowed by $20 \%$ when liver hepcidin was suppressed by heparin (Fig. 3F, $\mathrm{P}<0.05$ ). Moreover, the overall health conditions of the mice administrated with heparin were not undermined. No body weight loss was found, and no abnormal activity or diets were observed. These data together suggested that inhibition of hepcidin production conferred significant inhibition on tumor growth by reducing intracellular iron concentration in tumor cells.

\subsection{Increased hepatic hepcidin was driven by elevated iron, BMP6 and IL-6} in breast cancers

Although the complicated regulation of hepcidin under the normal setting has been recognized $[5,28]$, little has been investigated for hepcidin regulation in cancers. Thus, to elucidate the mechanism underlying the increased circulating hepcidin in breast cancers, we examined the upstream regulators of hepcidin. Since iron/BMP6 and IL-6 are the fundamental regulators of hepcidin expression in the liver under the normal setting $[5,10]$, we assessed serum concentrations of iron, BMP6 and IL-6 in breast cancers. Serum iron concentration was increased approximately 2 fold in patients compared to that in healthy controls (Fig. 4A, P $<0.001$ ). BMP6 concentration was also increased in sera from patients compared to the control (Fig. $4 \mathrm{~B}, \mathrm{P}<0.05$ ), while BMP4 concentration was not significantly changed (Fig. S4). Moreover, serum IL-6 concentration in patients was 2.8 times higher than that in the control (Fig. $4 \mathrm{C}, \mathrm{P}<0.001$ ). These observations suggested that increased serum iron, BMP6 and IL-6 could likely account for the upregulation of hepatic hepcidin.

To test this hypothesis, we evaluated the stimulatory influence of sera on hepcidin expression in human hepatocyte SMMC-7721 cells. As shown in Fig. 4D, sera from patients robustly stimulated hepcidin expression in SMMC-7721 cells, especially with sera from patients with malignant tumors ( $>5$ fold), compared to the control $(\mathrm{P}<0.001)$. To substantiate the stimulating effect from each individual regulator in sera, we discriminated their separate contribution to hepcidin upregulation using Deferoxamine (DFO) to chelate serum iron, and specific antibodies (Abs) to neutralize BMP6 or IL-6, respectively. Blockade of 
(A)

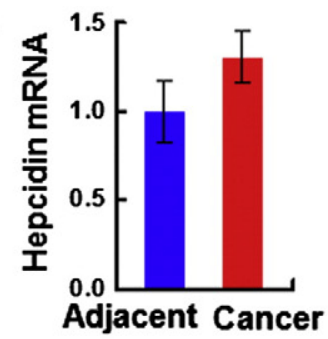

(B)

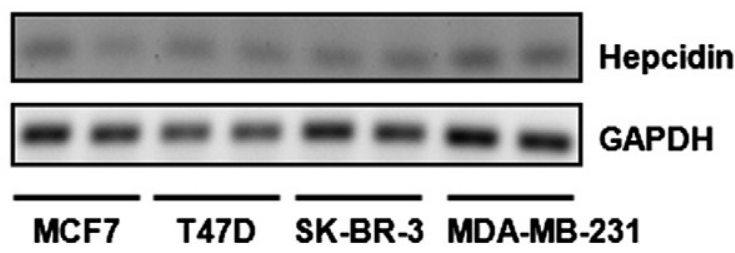

(C)

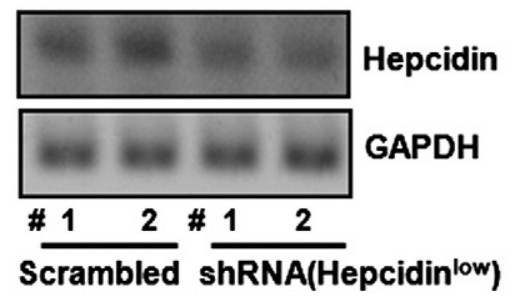

(D)
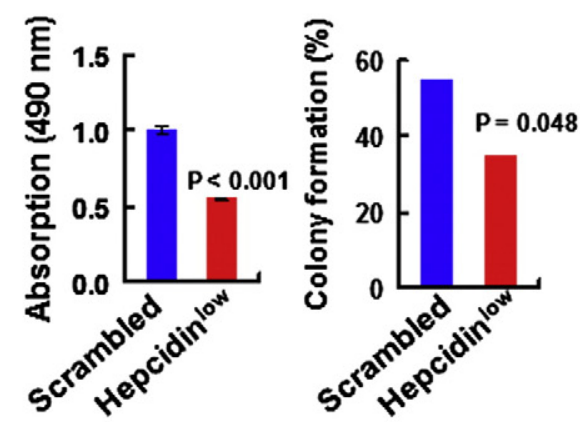

(F)
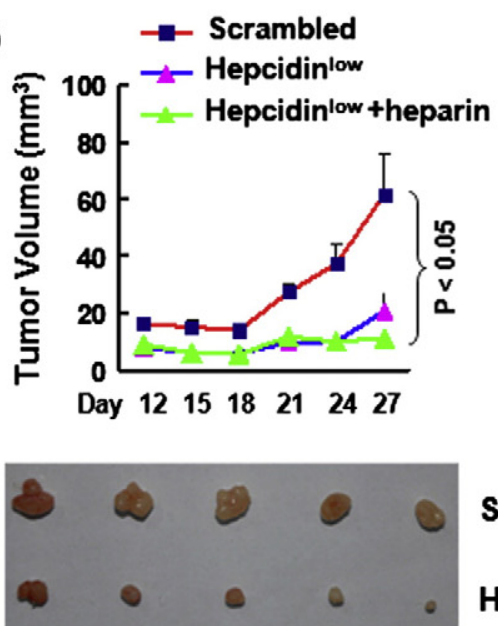

Scrambled

Hepcidin low

(E)
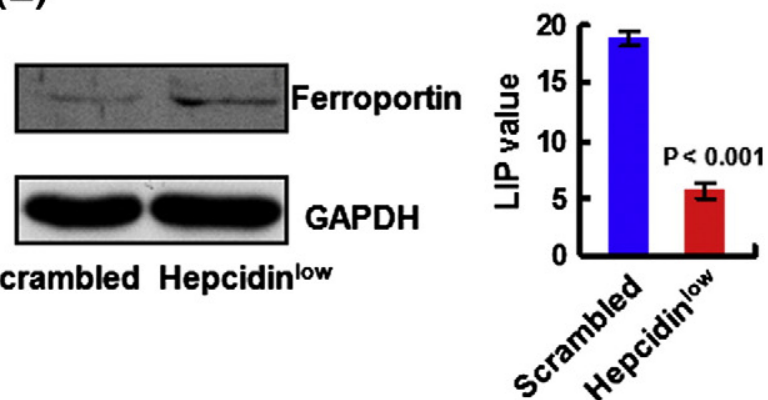

(G)

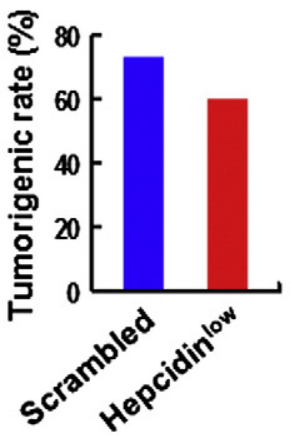

(H)

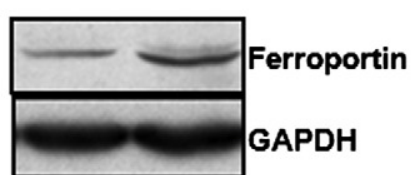

Scrambled Hepcidin'ow

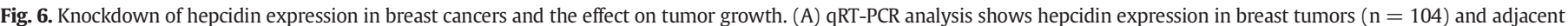

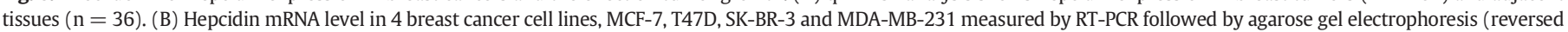

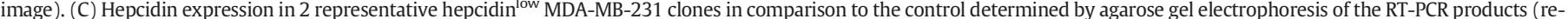

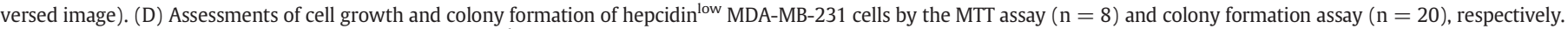

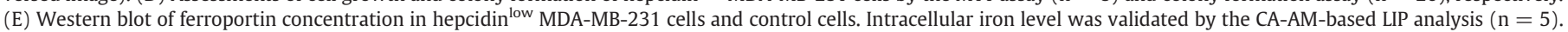

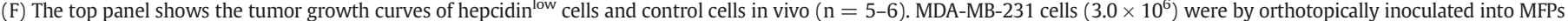

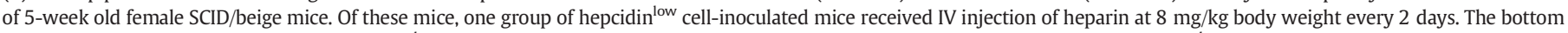

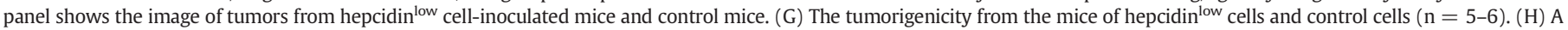
representative image of ferroportin concentration in tumors derived from hepcidin ${ }^{\text {low }}$ cells and control cells determined by Western blot. 
(A)
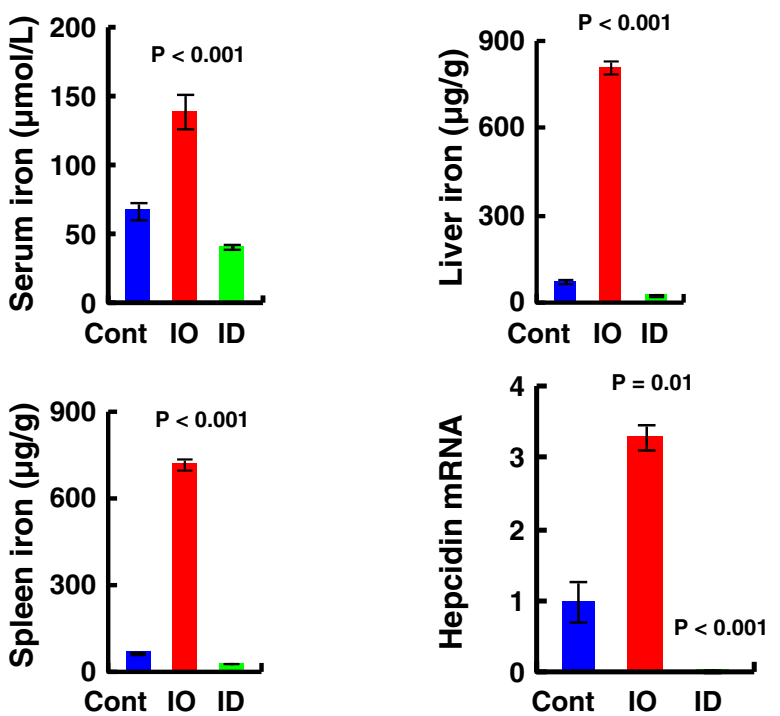

(B)

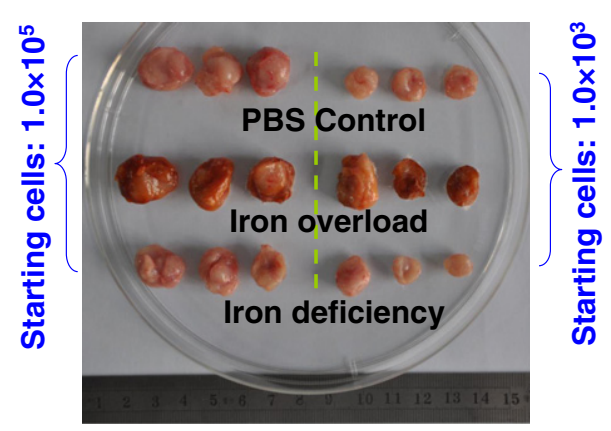

Fig. 7. Mouse models of iron overload and iron deficiency and the tumor growth. (A) Serum iron, spleen iron and liver iron were assessed in control mice, ironoverloaded mice (IO) and iron-deficient mice (ID) $(n=8-10)$. Hepatic hepcidin expression was examined in these mice by qRT-PCR. (B) Representative image of tumors derived from $1.0 \times 10^{5}$ or $1.0 \times 10^{3} 4 \mathrm{~T} 1$ cells.

these stimulators dramatically attenuated hepcidin expression in SMMC-7721 cells (Fig. 4E). Neutralization of BMP6 or IL-6 exerted a similar inhibitory effect on hepcidin expression $(\mathrm{P}<0.05)$, and simultaneous neutralization of BMP6 and chelation of iron with DFO further reduced hepcidin expression in SMMC-7721 cells relative to BMP6 neutralization only (Fig. 4E, $\mathrm{P}<0.05$ ). However, the greatest inhibitory effect on hepcidin expression was seen when neutralizing BMP6 and IL6 and chelating iron, simultaneously (Fig. 4E, P<0.05). Herein, DFO alone was used as a positive control to repress hepcidin expression $(\mathrm{P}<0.05)$, and normal IgG was used as a negative control for neutralization experiments (Fig. 4E). These results collectively indicated that iron, BMP6 and IL-6 jointly induced hepatic hepcidin expression, and that the concomitant increase of iron, BMP6 and IL- 6 was, at least partially, account for increased circulating hepcidin in breast cancers.

\subsection{BMP6 induction in response to excess iron}

The action of iron in upregulating hepcidin closely depends on BMP receptor-mediated signaling [28]. The details of how BMP6 and iron regulate hepcidin expression in vivo are not understood, and the main source of BMP6, especially in response to iron, has not been characterized. Moreover, with respect to these mechanisms, little is known in cancers. In an attempt to analyze BMP6 induction in response to iron in various organs, we surveyed BMP6 expression by utilizing a mouse model of iron overload. BMP6 mRNA content was assessed in the kidney, lung, spleen, heart, muscle, fat, duodenum and liver (Fig. 5A). Overall, BMP6 mRNA was relatively high in the kidney, lung, spleen and heart in comparison to other organs (Fig. 5B, $\mathrm{P}<0.05$ ). Upon iron stimulation, BMP6 expression was increased approximately by 2 fold in the kidney, spleen, duodenum and liver $(\mathrm{P}<0.05)$, but not significantly altered in other organs (Fig. 5B). Our results demonstrated that the liver and duodenum plus kidney and spleen were the major source organs of BMP6 synthesis in response to iron. In contrast to BMP6, IL-6 expression was changed little by iron loading (Fig. 5C), in agreement with previous results [29]. These data further supported the concept that iron-transferrin-transferrin receptor and BMP6BMPR signaling jointly modulate hepcidin expression in response to changes in iron levels, and that the induction of the BMPR agonist ligand BMP6 is stimulated by iron.

\subsection{Downregulation of tumor hepcidin suppressed tumor growth}

Although cancer cells also express hepcidin $[15,16]$, the biological effects of tumor hepcidin have not been investigated yet. In this context, we first assessed the expression levels of hepcidin in our tumor specimens. We uncovered that hepcidin expression was increased by $30 \%$, although not significantly, in tumors compared to adjacent tissues (Fig. 6A, P> 0.05), consistent with its marginal significance as a prognostic marker by itself [13]. Since the role of tumor hepcidin in cell growth has not been investigated thus far, we examined the effects of hepcidin downregulation on tumor growth. As the RT-PCR analysis indicated, MDA-MB-231 cells had relatively high hepcidin expression compared to MCF-7, T47D and SK-BR-3 (Fig. 6B). We stably knocked down endogenous hepcidin expression in MDA-MB-231 using lentiviral-based shRNA constructs. Hepcidin level was reduced by 40 $50 \%$ in shRNA-infected cells compared to scrambled RNA-infected cells, as two representative hepcidin ${ }^{\text {low }}$ clones revealed a pronounced loss of hepcidin expression (Fig. 6C). Upon hepcidin reduction, cell growth was greatly hampered, as the MTT assay showed a $>40 \%$ decrease in cell growth of hepcidin ${ }^{\text {low }}$ cells compared to the control (Fig. 6D, $\mathrm{P}<0.001$ ). Also, colony-forming activity was decreased in hepcidin ${ }^{\text {low }}$ cells compared to the control (35\% vs. 55\%, Fig. 6D, $\mathrm{P}<0.05)$. Subject to hepcidin decrease, ferroportin concentration in hepcidin ${ }^{\text {low }}$ cells was higher than that in control cells (Fig. 6E), and intracellular LIP in hepcidin ${ }^{\text {low }}$ cells was consequently reduced by $70 \%$ (Fig. $6 \mathrm{E}, \mathrm{P}<0.001$ ). Thereafter, the in vivo growth of hepcidin ${ }^{\text {low }}$ cells was determined in mice. Tumor growth was substantially inhibited, and the final tumor weight was reduced by $70 \%$ in mice inoculated with hepcidin ${ }^{\text {low }}$ cells compared to that in mice inoculated with scrambled control cells (Figs. 6F and S5, P $<0.05$ ). Moreover, the percentage of tumorigenesis was also decreased for hepcidin ${ }^{\text {low }}$ cells compared to control cells (60\% vs. $73 \%$, Fig. 6G), consistent with the results of the in vitro colony formation assay (Fig. 6D). Ferroportin concentration was increased by approximately $60 \%$ in tumors derived from hepcidin ${ }^{\text {low }}$ cells compared to that in tumors derived from control cells (Fig. 6H). These data suggested that increasing ferroportin concentration by suppressing tumor cells' autocrine hepcidin could elicit a substantial inhibition on tumor growth.

\subsection{Iron and IL-6 jointly promoted tumor cell growth}

Several surveys with a large number of participants have revealed that high body iron stores increase the risk of cancers and worsen prognosis of cancers [30,31]. The causes for elevated body iron stores have not yet been identified. To date, dietary intake of iron is assumed to be an important source for elevated iron store. For example, a case-control survey of 3452 breast cancer patients and 3474 age-frequency-matched healthy controls in China showed that intake of meat-derived hemeiron increased the risk of breast cancer in Chinese women [32]. Similar observations were found for cancer patients in the US [33]. Among additional breast cancer associated factors, menopause is believed to 
(A)

(B)

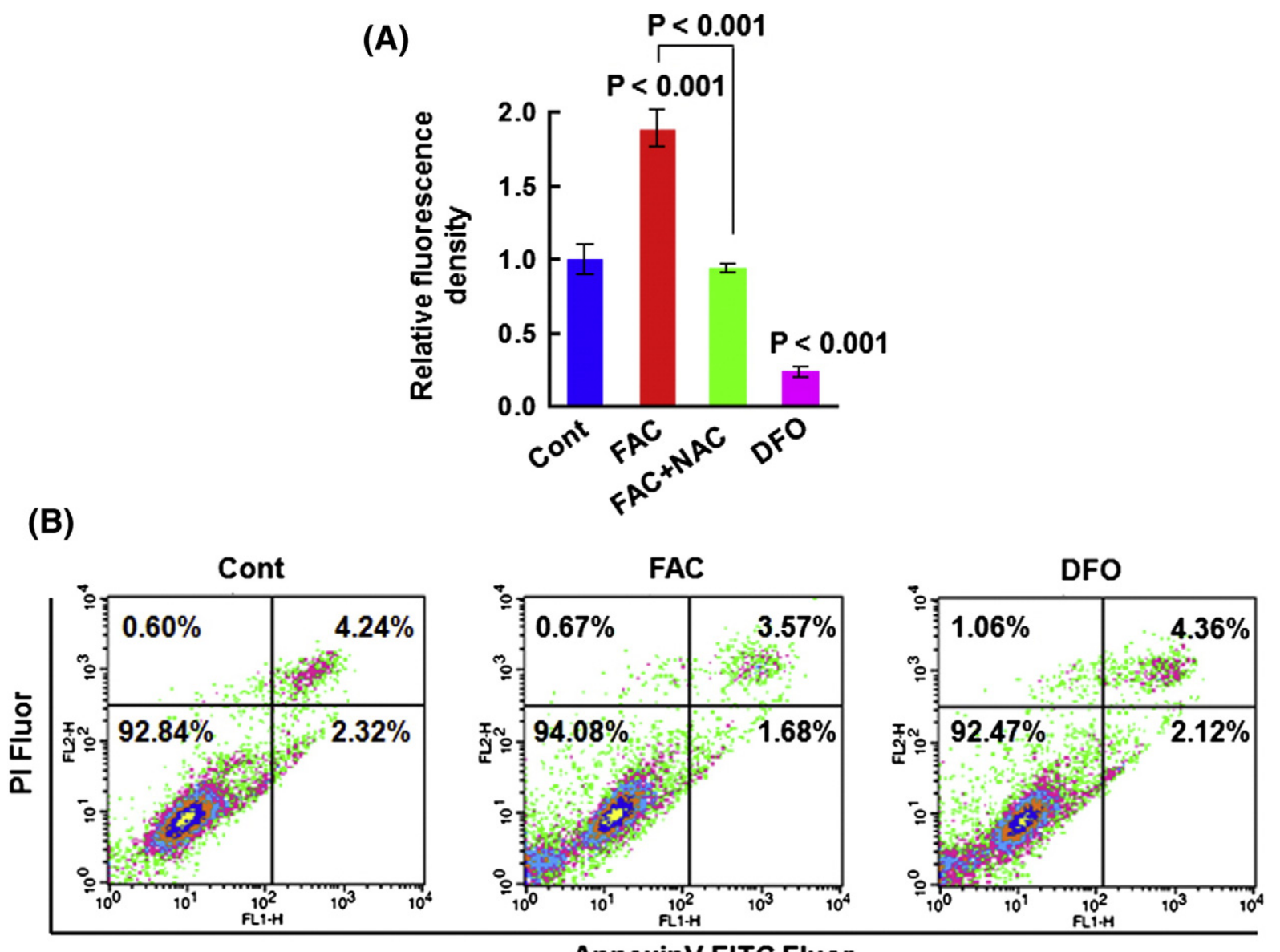

\section{AnnexinV-FITC Fluor}

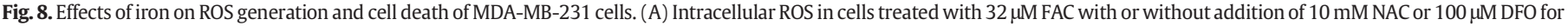
$2 \mathrm{~h}(\mathrm{n}=6)$. (B) Representative FACS data of cell death upon iron $(32 \mu \mathrm{M}$ FAC) and iron chelator (100 $\mu \mathrm{M}$ DFO) for $24 \mathrm{~h}$.

contribute to increased body iron mass [34], meanwhile high estrogen and alcohol intake could promote iron release from iron-bound proteins into plasma $[35,36]$. To validate the tumorigenic effect of iron, we compared iron-overloaded and iron deficient mice. As shown in Fig. 7A, mouse models of iron overload and iron deficiency were well established, as iron content in the serum, liver and spleen was dramatically increased or reduced $(\mathrm{P}<0.001)$. Hepatic hepcidin expression was also correspondingly regulated in response to the alterations of iron concentration, as its level was dramatically increased in iron-overloaded (IO) mice and was substantially decreased in irondeficient (ID) mice (Fig. 7A, $\mathrm{P}<0.001$ ). Subject to body iron changes, iron content in tumors derived from mouse 4T1 cells in Balb/c mice was consequently increased in IO mice or decreased in ID mice (Fig. S6, P $<0.05$ ), and tumor growth was also significantly enhanced or slowed (Fig. 7B), consistent with previous results [37,38]. In agreement with the results in mice, iron supplement (FAC) for $48 \mathrm{~h}$ greatly promoted cell growth for $4 \mathrm{~T} 1$ cells, whereas iron chelation with DFO significantly inhibited cell growth, as reflected by the MTT assay (Fig. S7).

The tumorigenic effect of iron has been attributed to several factors, such as overproduction of ROS and free radicals through irondependent Fenton reaction, induction of oxidative responsive transcriptional factors and pro-inflammatory cytokines and iron-mediated hypoxia signaling [39-42]. Consistent with previous studies [43,44], we demonstrated that iron treatment (FAC $32 \mu \mathrm{M}$, similar to the mean iron concentration in our breast cancer patients) could induce about 1.9-fold increase of intracellular ROS level in MBA-MB-231 cells compared to the control (Fig. 8A, P $<0.001$ ), while DFO significantly reduced ROS generation (Fig. $8 \mathrm{~A}, \mathrm{P}<0.001$ ). The pretreatment of NAC, a ROS scavenger, could significantly decrease ROS production elicited by iron (Fig. $8 \mathrm{~A}, \mathrm{P}<0.001$ ). Iron treatment at the current concentration had little effect on cell death as evidenced by Fluorescence Activated Cell Sorting (FACS) analysis with Annexin V and PI staining (Fig. 8B). These data support the concept that moderate induction of ROS in cancer cells would contribute to cell proliferation rather than triggering cell death $[42,45]$.

To define the separate effects of iron, IL-6 and BMP6 on tumor development, we assayed cell growth of MDA-MB-231 cells by chelating endogenous iron or neutralizing endogenous BMP6 or IL-6 in sera from patients. The MTT assay and the BrdU incorporation assay indicated that chelating serum iron or neutralizing serum IL-6 significantly reduced cell growth (Fig. 9A \& B, P < 0.05). IL-6 was thus demonstrated to stimulate cell proliferation, in agreement with previous studies performed in breast cancer cells and other cells [46,47]. The elevation of serum IL-6 is thought to stem from chronic inflammatory response to cancer [48]. Additionally, the blockade of both iron and IL-6 further decreased cell growth (Fig. $9 A \& B, P<0.05$ ), suggesting that increased iron and IL-6 were both implicated in promoting tumor cell growth. BMP6 neutralization in sera exerted little influence on cell growth (Fig. 9A), implying that BMP6 was not directly involved in regulating cancer cell growth, in agreement with the previous results [49,50]. DFO (at $100 \mu \mathrm{M}$ ) was used as a control to repress cell proliferation (Fig. 9A \& $\mathrm{B}, \mathrm{P}<0.001$ ). In the neutralization experiments, normal $\operatorname{IgG}$ at a similar concentration to IL-6 and BMP6 Abs had little effect on cell growth 
(A)

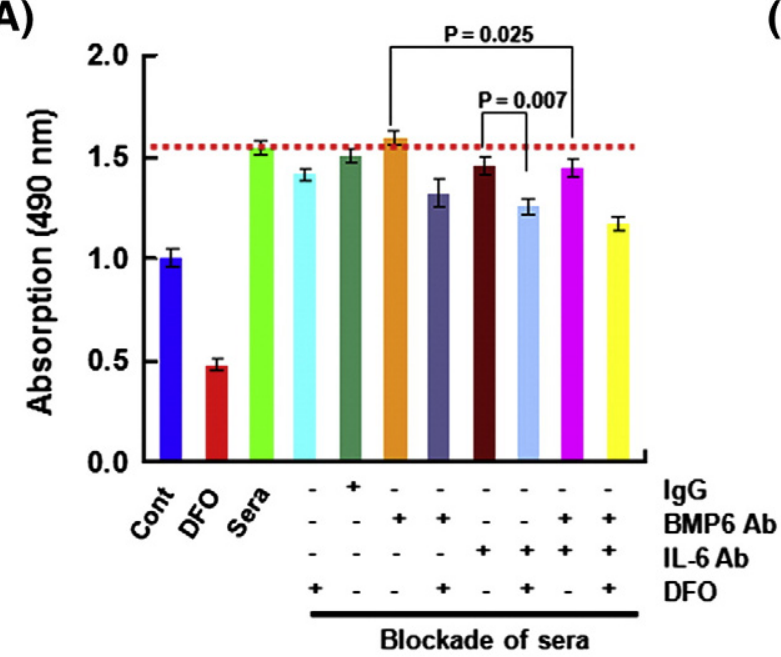

(B)

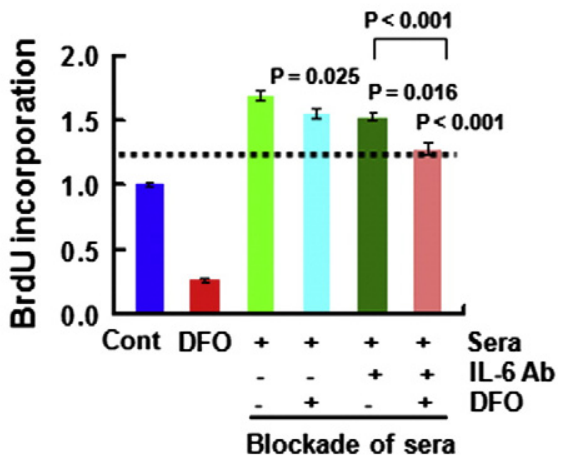

(C)
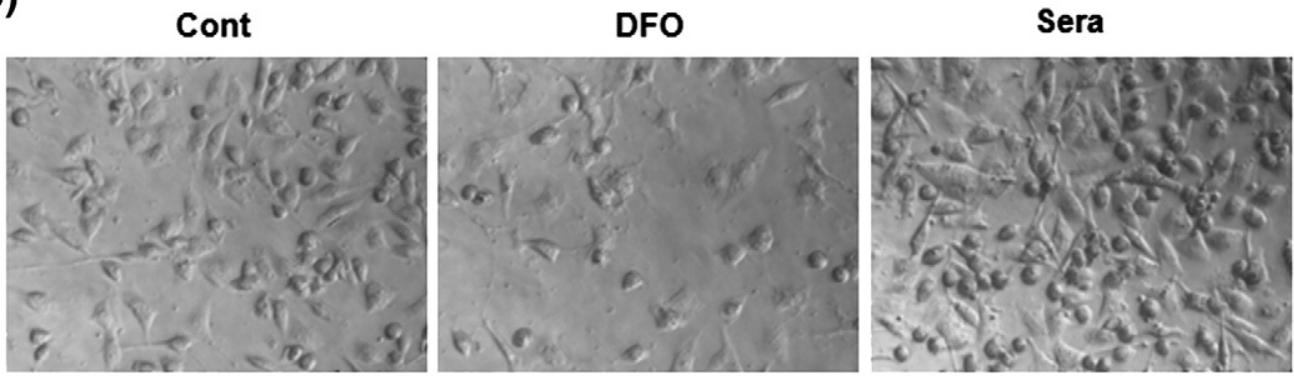

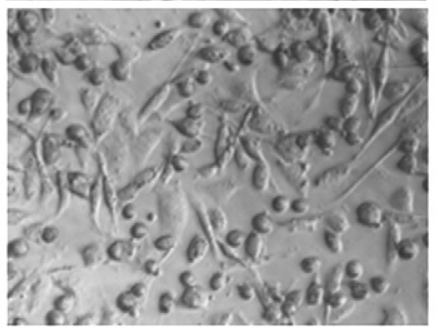

Sera + DFO

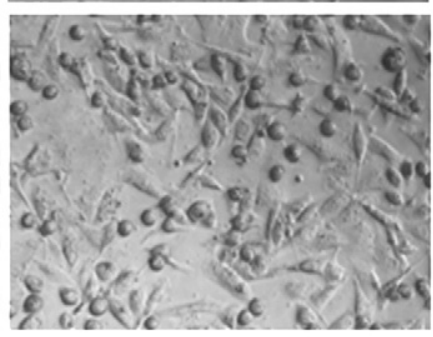

Sera + IL6 Ab

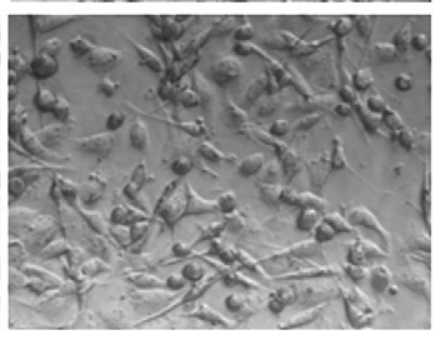

Sera + IL6 Ab + DFO

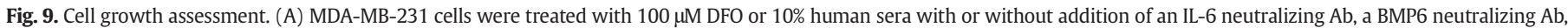

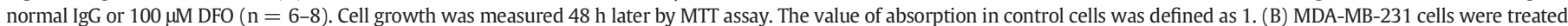

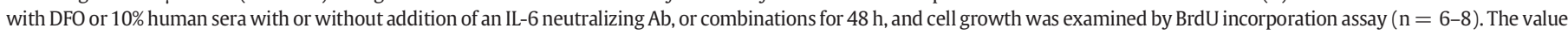

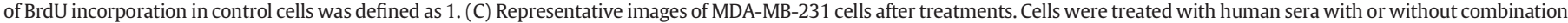
of the IL- 6 neutralizing Ab and DFO for $48 \mathrm{~h}$. Original magnification, $\times 200$.

(Fig. 9A). Representative images for cells upon different treatments as described above are shown in Fig. 9C. These results together recognized a concomitant role of iron and IL-6 in promoting tumor cell growth.

\section{Discussion}

Breast cancer is the most common cancer among women and the leading cause of cancer-related mortality of women worldwide [51, 52]. Cancers are often associated with disordered systemic iron homeostasis [53,54], which in turn promotes tumor development through various signaling pathways, such as iron-induced cell growth and oxidative stress $[34,55,56]$. Clinical studies have noted that there is a positive correlation between body iron burden and the risk of developing tumors [34,57]. Although a number of studies have documented that diminishing iron supply to tumor cells could impede tumor growth in experimental models $[58,59]$ and even patients with various cancers [60,61], the molecular bases of the altered iron homeostasis keep largely unexplored in cancers thus far. Recent studies suggest that disordered iron homeostasis in cancers is due to abnormal regulation of hepcidin and ferroportin, both of which have prognostic significance in patients $[11,12,62,63]$. Nonetheless, a detailed elucidation of the adaptive hepcidin-ferroportin signaling in cancers has not been reached. Here, we uncover the mechanisms underlying the abnormal regulation of the hepcidin-ferroportin signaling in breast cancers.

Systemic iron homeostasis is fundamentally governed by the hepcidin-ferroportin regulatory axis under normal physiological conditions [5,64]. Hepcidin plays a central role in controlling iron flows, through suppressing iron absorption from the duodenum and iron egress from macrophages and hepatocytes $[5,9,28]$. The primary molecular action of hepcidin is to induce degradation of ferroportin, resulting in increased cellular iron concentration [8]. Although increased serum hepcidin was observed in myeloma, renal cell carcinoma and prostate cancer $[11,12,14]$, hepcidin level in breast cancers is unclear so far. Moreover, the biological influence of increased serum hepcidin on tumor development and the mechanisms underlying deregulated iron homeostasis in cancers have not been identified yet. 


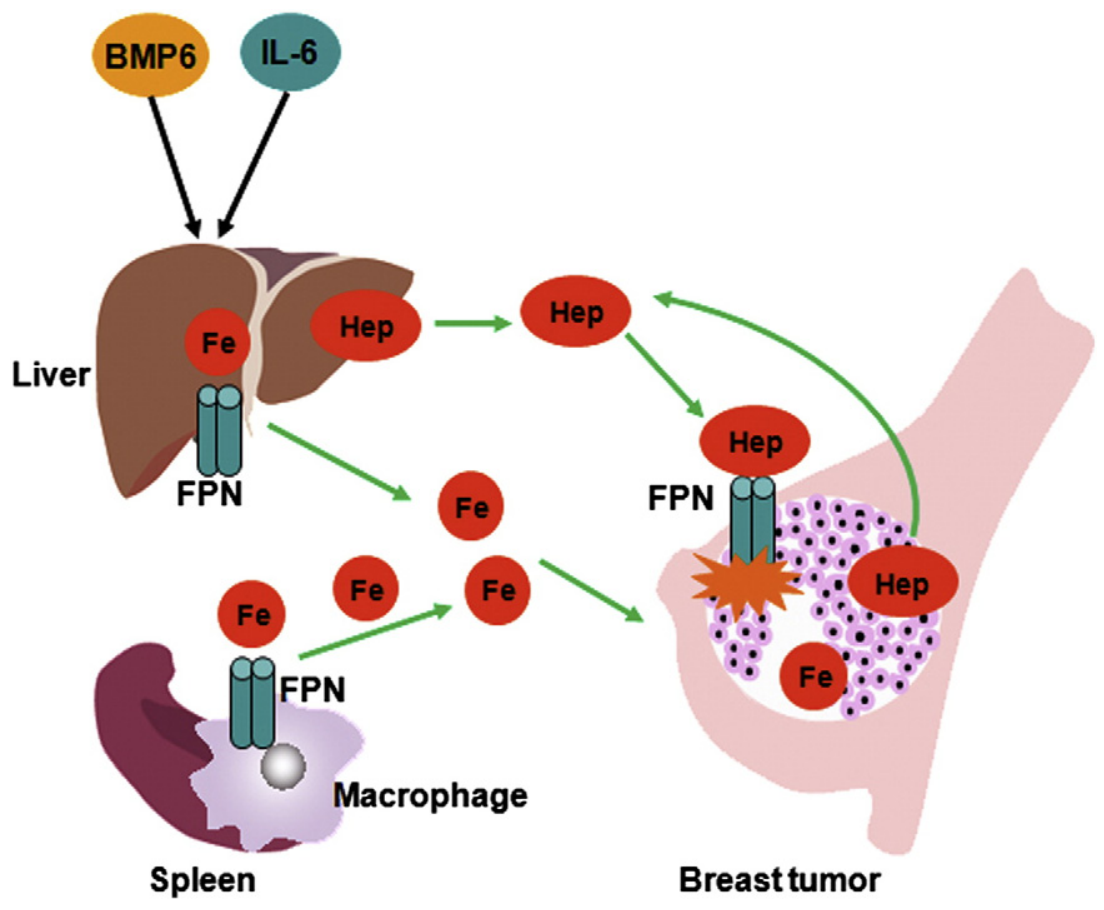

Fig. 10. A schematic diagram delineating the hepcidin-ferroportin signaling in governing systemic and tumor iron homeostasis in breast cancer.

In the current study, our results revealed that serum hepcidin was increased in breast cancers, and diminishing hepcidin significantly suppressed breast cancer progression. We demonstrated that reduction of hepcidin synthesis by heparin caused robust inhibition of tumor growth due to diminished intracellular iron retention. This finding revealed that circulating hepcidin secreted from the liver exerted a robust effect on ferroportin-mediated iron export in tumor cells, and hepcidin deficit led to increased iron egress from tumor cells with a resultant repression of tumor growth. As previously reported [65], in addition to an established antithrombotic effect, heparin also exerts a direct antitumor effect through inhibition on angiogenesis, cellcell interaction and extracellular-matrix protease heparanase. Our experiments revealed a novel inhibitory effect of heparin on breast tumor progression through suppressing hepcidin, which surely contributes to the overall heparin-mediated antitumor effects; however, this mechanism has not been recognized before. Therefore, inhibition of hepcidin (such as through chemical compounds) may therefore prove to be a prospective approach to restrain tumor.

Thus far, there have been few studies focusing on the molecular bases of abnormal serum hepcidin upon cancers. Under the normal condition, hepatic hepcidin expression is prominently induced by erythropoietic demand, iron burden and inflammatory stimuli [66-68], of which the BMP family members and the IL-6 family cytokines are the essential upstream regulators $[68,69]$. Recent studies suggest that BMP6, rather than other BMP family members, is the key endogenous regulator of hepatic hepcidin expression at least in mice [70], and BMP6 likely governs the basal expression of hepatic hepcidin [71]. We here uncovered increased concentrations of BMP-6, IL-6 and iron in sera from breast cancer patients, and verified the simulating effects of serum IL-6, BMP-6 and iron on hepatic hepcidin expression. Regarding the source of BMP6, there has been no conclusive answer, with even contradictory results [72,73]. We here demonstrated that BMP6 synthesis was significantly enhanced in the kidney, spleen, duodenum and liver, but not in other organs, upon iron stimulation. These data suggest that these 4 organs jointly contribute to BMP6 induction for the purpose of hepcidin stimulation in response to iron. Together, increased iron, BMP-6 and IL-6 add tumorigenic propensity to cancer cells through, at least partially, concomitantly elevating hepatic expression.

Pinnix's study reveals that the mRNA level of tumor hepcidin could only discriminate a marginal significance for the patient prognosis in a combined cohort with 504 patients [13]. However, when combining both hepcidin and ferroportin, the greatest significant metastasis-free survival advantage was recognized for patients with low-hepcidin and high-ferroportin expressions, suggesting that the hepcidin expression level could add additional enhancive power to the prognostic significance of ferroportin in breast cancer patients [13]. In parallel to Pinnix's [13] finding, we found that hepcidin was marginally increased in breast tumors; whereas tumor ferroportin was greatly decreased in tumors. Knocking-down tumor hepcidin expression elicited inhibition of tumor growth of MDA-MB-231 cells due to diminished intracellular iron retention. These findings suggested that reduction of tumor hepcidin would considerably relieve iron retention in tumor cells, and thus limit the tumorigenic effect of iron.

\section{Conclusions}

To summarize, we gain novel insights into the molecular bases on which tumor cells request more iron for cell growth. Increased hepatic and tumor hepcidin and decreased tumor ferroportin jointly inhibit ferroportin-conducted iron egress and thereby increase tumor iron concentration. Increased plasma iron, BMP6 and IL- 6 jointly promote the production of hepatic hepcidin, and enhanced IL- 6 adds additional tumorigenic effects of iron on favoring tumor cell growth. As illustrated in Fig. 10, misregulated hepcidin-ferroportin signaling contributes to breast tumor growth through altering systemic and tumor iron homeostasis. This study overall signifies a crucial role of deregulated hepcidin-ferroportin signaling in enforcing tumor growth.

\section{Conflict of interests}

The authors declare no competing financial interests. 


\section{Authors' contributions}

SL conceived and designed the study. SZ, YC, WG, YL, DZ, and SL carried out the experiments and analyzed the data. YL, DZ, YX, EN and TG contributed reagents and materials. SL, SZ, TG and YC wrote and revised the manuscript.

\section{Acknowledgments}

This work was supported by a grant under the national "973" program (grant number: 2014CB932000), the Strategic Priority Research Program of the Chinese Academy of Sciences (grant no. XDB14000000) and the National Natural Science Foundation of China (grant numbers: 21377159, 21177151, 21207152). We thank all the laboratory members for their great assistance with experiments and reagents.

\section{Appendix A. Supplementary data}

Supplementary data to this article can be found online at http://dx. doi.org/10.1016/j.cellsig.2014.07.029.

\section{References}

[1] M.R. Bedford, S.J. Ford, R.D. Horniblow, T.H. Iqbal, C. Tselepis, J. Clin. Pharmacol. 53 (2013) 885-891.

[2] S.V. Torti, F.M. Torti, Nat. Rev. Cancer 13 (2013) 342-355

[3] A. Richardson, Z. Kovacevic, D.R. Richardson, Crit. Rev. Oncog. 18 (2013) 409-434.

[4] M.W. Hentze, M.U. Muckenthaler, N.C. Andrews, Cell 117 (2004) 285-297.

[5] T. Ganz, Blood 117 (2011) 4425-4433.

[6] P. Brissot, E. Bardou-Jacquet, A.-M. Jouanolle, O. Loréal, Trends Mol. Med. 17 (2011) 707-713.

[7] C.H. Park, E.V. Valore, A.J. Waring, T. Ganz, J. Biol. Chem. 276 (2001) 7806-7810.

[8] E. Nemeth, M.S. Tuttle, J. Powelson, M.B. Vaughn, A. Donovan, D.M. Ward, T. Ganz, J. Kaplan, Science 306 (2004) 2090-2093.

[9] H. Drakesmith, A.M. Prentice, Science 338 (2012) 768-772.

[10] R.E. Fleming, P. Ponka, N. Engl. J. Med. 366 (2012) 348-359.

[11] T. Ganz, G. Olbina, D. Girelli, E. Nemeth, M. Westerman, Blood 112 (2008) 4292-4297.

[12] K. Maes, E. Nemeth, G.D. Roodman, A. Huston, F. Esteve, C. Freytes, N. Callander, E. Katodritou, L. Tussing-Humphreys, S. Rivera, K. Vanderkerken, A. Lichtenstein, T. Ganz, Blood 116 (2010) 3635-3644.

[13] Z.K. Pinnix, L.D. Miller, W. Wang, R. D'Agostino, T. Kute, M.C. Willingham, H. Hatcher, L. Tesfay, G. Sui, X. Di, S.V. Torti, F.M. Torti, Sci. Transl. Med. 2 (2010) 43 ra56.

[14] T. Tanno, A. Rabel, M. Alleyne, Y.T. Lee, W.L. Dahut, J.L. Gulley, J.L. Miller, BJU Int. 107 (2011) 678-679.

[15] T. Kamai, N. Tomosugi, H. Abe, K. Arai, K.-I. Yoshida, BMC Cancer 9 (2009) 270.

[16] Y. Sakuraoka, T. Sawada, T. Shiraki, K. Park, Y. Sakurai, N. Tomosugi, K. Kubota, J. World Gastroenterol. 18 (2012) 3727-3731.

[17] L.D. Miller, L.G. Coffman, J.W. Chou, M.A. Black, J. Bergh, R. D'Agostino, S.V. Torti, F.M. Torti, Cancer Res. 71 (2011) 6728-6737.

[18] S. Liu, R.H. Goldstein, E.M. Scepansky, M. Rosenblatt, Cancer Res. 69 (2009) 8742-8751.

[19] S. Liu, S. Li, Y. Du, PLoS One 5 (2010) e11272.

[20] X. Gao, M. Qian, J.L. Campian, J. Marshall, Z. Zhou, A.M. Roberts, Y.J. Kang, S.D. Prabhu, X.-F. Sun, J.W. Eaton, Free Radic. Biol. Med. 49 (2010) 401-407.

[21] A.-P. Han, C. Yu, L. Lu, Y. Fujiwara, C. Browne, G. Chin, M. Fleming, P. Leboulch, S.H. Orkin, J.-J. Chen, EMBO J. 20 (2001) 6909-6918.

[22] G. Qu, C. Zhang, L. Yuan, J. He, Z. Wang, L. Wang, S. Liu, G. Jiang, Nanoscale 4 (2012) 2239-2244.

[23] S. Liu, R.N.V.S. Suragani, F. Wang, A. Han, W. Zhao, N.C. Andrews, J.-J. Chen, J. Clin. Invest. 117 (2007) 3296-3305.

[24] E. Prus, E. Fibach, Cytometry A 73A (2008) 22-27.

[25] F.W. Huang, J. Clin. Invest. 115 (2005) 2187-2191.

[26] C. Pigeon, G. Ilyin, B. Courselaud, P. Leroyer, B. Turlin, P. Brissot, O. Loréal, J. Biol. Chem. 276 (2001) 7811-7819.

[27] M. Poli, D. Girelli, N. Campostrini, F. Maccarinelli, D. Finazzi, S. Luscieti, A. Nai, P. Arosio, Blood 117 (2011) 997-1004.
[28] R. Evstatiev, C. Gasche, Gut 61 (2012) 933-952.

[29] Oldenburg, H. Van Berge, Rennick, A. Van, Koningsberger, Eur. J. Clin. Investig. 30 (2000) 505-510.

[30] P. Knekt, A. Reunanen, H. Takkunen, A. Aromaa, M. Heliövaara, T. Hakuunen, Int. J. Cancer 56 (1994) 379-382.

[31] R.G. Stevens, B.I. Graubard, M.S. Micozzi, K. Neriishi, B.S. Blumberg, Int. J. Cancer 56 (1994) 364-369.

[32] A.R. Kallianpur, S.A. Lee, Y.T. Gao, W. Lu, Y. Zheng, Z.X. Ruan, Q. Dai, K. Gu, X.O. Shu, W. Zheng, Breast Cancer Res. Treat. 107 (2008) 123-132.

[33] L.M. Ferrucci, A.J. Cross, B.I. Graubard, L.A. Brinton, C.A. McCarty, R.G. Ziegler, X. Ma, S.T. Mayne, R. Sinha, Br. J. Cancer 101 (2009) 178-184.

[34] X. Huang, Lancet Oncol. 9 (2008) 803-807.

[35] R.M. Wright, J.L. McManaman, J.E. Repine, Free Radic. Biol. Med. 26 (1999) 348-354

[36] S. Wyllie, J.G. Liehr, Arch. Biochem. Biophys. 346 (1997) 180-186.

[37] H.-W.L. Hann, M.W. Stahlhut, B.S. Blumberg, Cancer Res. 48 (1988) 4168-4170.

[38] C.P. Siegers, D. Bumann, H.D. Trepkau, B. Schadwinkel, G. Baretton, Cancer Lett. 65 (1992) 245-249.

[39] W.E. Naugler, M. Karin, Trends Mol. Med. 14 (2008) 109-119.

[40] J.Y. Choi, M.L. Neuhouser, M.J. Barnett, C.C. Hong, A.R. Kristal, M.D. Thornquist, I.B King, G.E. Goodman, C.B. Ambrosone, Carcinogenesis 29 (2008) 964-970.

[41] J. Dai, J. Jian, M. Bosland, K. Frenkel, G. Bernhardt, X. Huang, Breast 17 (2008) $172-179$.

[42] L.M. Bystrom, M.L. Guzman, S. Rivella, Antioxid. Redox Signal. 20 (2013) 1917-1924

[43] C.P. LeBel, H. Ischiropoulos, S.C. Bondy, Chem. Res. Toxicol. 5 (1992) 227-231.

[44] J. Amer, H. Ghoti, E. Rachmilewitz, A. Koren, C. Levin, E. Fibach, Br. J. Haematol. 132 (2006) 108-113.

[45] J.P. Fruehauf, F.L. Meyskens Jr., Clin. Cancer Res. 13 (2007) 789-794.

[46] S. Grivennikov, E. Karin, J. Terzic, D. Mucida, G.-Y. Yu, S. Vallabhapurapu, J. Scheller S. Rose-John, H. Cheroutre, L. Eckmann, M. Karin, Cancer Cell 15 (2009) 103-113.

[47] D. Conze, L. Weiss, P.S. Regen, A. Bhushan, D. Weaver, P. Johnson, M. Rincón, Cancer Res. 61 (2001) 8851-8858.

[48] M.F. Neurath, S. Finotto, Cytokine Growth Factor Rev. 22 (2011) 83-89.

[49] M. Takahashi, F. Otsuka, T. Miyoshi, H. Otani, J. Goto, M. Yamashita, T. Ogura, H. Makino, H. Doihara, J. Endocrinol. 199 (2008) 445-455.

[50] J. Du, S. Yang, Z. Wang, C. Zhai, W. Yuan, R. Lei, J. Zhang, T. Zhu, J. Cell. Biochem. 103 (2008) 1584-1597.

[51] C. DeSantis, R. Siegel, P. Bandi, A. Jemal, CA Cancer J. Clin. 61 (2011) 408-418.

[52] R. Siegel, D. Naishadham, A. Jemal, CA Cancer J. Clin. 62 (2012) 10-29.

[53] T. Ganz, E. Nemeth, Annu. Rev. Med. 62 (2011) 347-360.

[54] J. Cullis, Clin. Med. 13 (2013) 193-196.

[55] R.G. Stevens, D.Y. Jones, M.S. Micozzi, P.R. Taylor, N. Engl. J. Med. 319 (1988) 1047-1052.

[56] A.J. Cross, R. Sinha, R.J. Wood, X. Xue, W.-Y. Huang, M. Yeager, R.B. Hayes, M.J. Gunter, Cancer Prev. Res. 4 (2011) 1465-1475.

[57] M.K. Siddiqui, Jyoti, S. Singh, P.K. Mehrotra, K. Singh, R. Sarangi, Environ. Int. 32 (2006) 630-637.

[58] D.S. Kalinowski, D.R. Richardson, Pharmacol. Rev. 57 (2005) 547-583.

[59] A.M. Merlot, D.S. Kalinowski, D.R. Richardson, Antioxid. Redox Signal. 18 (2013) 973-1006.

[60] A. Donfrancesco, G. Deb, C. Dominici, D. Pileggi, M.A. Castello, L. Helson, Cancer Res. 50 (1990) 4929-4930.

[61] P.M. Rothwell, F.G.R. Fowkes, J.F.F. Belch, H. Ogawa, C.P. Warlow, T.W. Meade, Lancet 377 (2011) 31-41.

[62] D.G. Ward, K. Roberts, M.J. Brookes, H. Joy, A. Martin, T. Ismail, R. Spychal, T. Iqbal, C Tselepis, World J. Gastroenterol. 14 (2008) 1339-1345.

[63] Y. Sakuraoka, T. Sawada, T. Shiraki, K. Park, Y. Sakurai, N. Tomosugi, K. Kubota, World J. Gastroenterol. 18 (2012) 3727-3731.

[64] M.W. Hentze, M.U. Muckenthaler, B. Galy, C. Camaschella, Cell 142 (2010) 24-38.

[65] L. Borsig, Prog. Mol. Biol. Transl. Sci. 93 (2010) 335-349.

[66] M.D. Knutson, Annu. Rev. Nutr. 30 (2010) 149-171.

[67] J.P. Pinto, S. Ribeiro, H. Pontes, S. Thowfeequ, D. Tosh, F. Carvalho, G. Porto, Blood 111 (2008) 5727-5733.

[68] D.M. Wrighting, N.C. Andrews, Blood 108 (2006) 3204-3209.

[69] J. Truksa, P. Lee, E. Beutler, Blood 113 (2009) 688-695.

[70] B. Andriopoulos Jr., E. Corradini, Y. Xia, S.A. Faasse, S. Chen, L. Grgurevic, M.D Knutson, A. Pietrangelo, S. Vukicevic, H.Y. Lin, J.L. Babitt, Nat. Genet. 41 (2009) 482-487.

[71] G. Casanovas, K. Mleczko-Sanecka, S. Altamura, M.W. Hentze, M.U. Muckenthaler, J. Mol. Med. 87 (2009) 471-480.

[72] S. Arndt, U. Maegdefrau, C. Dorn, K. Schardt, C. Hellerbrand, A.-K. Bosserhoff, Gastroenterology 138 (2010) 372-382.

[73] L. Kautz, C. Besson-Fournier, D. Meynard, C. Latour, M.-P. Roth, H. Coppin, Haematologica 96 (2011) 199-203. 